\title{
As dinâmicas da Pós-graduação em Santa Catarina: evolução e perspectivas (1969 - 2018)
}

The dynamics of the graduate education in Santa Catarina: evolution and perspectives (1969-2018)

Joviles Vitório Trevisol ${ }^{1}$ - ${ }^{1}$ Universidade Federal da Fronteira Sul | Programa de Pós-Graduação em Educação | Chapecó | SC | Brasil. Contato: joviles.trevisol@uffs.edu.br. ORCID: https://orcid.org/0000-0001-9873-2688

Sherlon Cristina de Bastiani ${ }^{2}$ - ${ }^{2}$ Universidade Federal da Fronteira Sul | Programa de Pós-Graduação em Educação | Chapecó | SC | Brasil. Contato: sherlondebastiani@gmail.com.

ORCID: https://orcid.org/0000-0002-7577-0021

André Brasil ${ }^{3}$ - ${ }^{3}$ Universiteit Leiden | Centre of Science and Technology Studies | Leiden | Holanda. Contato: andre.brasil@icloud.com. ORCID: https://orcid.org/0000-0003-1832-5199

Resumo: A pós-graduação cresceu de forma exponencial nas últimas décadas no Brasil. Entre 1998 e 2018, o Sistema Nacional de Pós-Graduação (SNPG) cresceu $188 \%$ e o número de matrículas em mestrados e doutorados, $289 \%$. No ano de 2017 foram titulados 21.393 doutores e 61.147 mestres, inclusive já superando uma das metas do Plano Nacional de Educação para 2024, que previa a titulação de 60 mil mestres por ano. Tal expansão ocorreu em todo o país, fato que torna relevantes os estudos para compreender as dinâmicas, as especificidades e as variações entre as regiões, estados da federação e segmentos das instituições que ofertam os programas (públicas e privadas). Com isso em mente, o presente artigo analisa a expansão da pós-graduação brasileira tomando como referência um estado da federação: Santa Catarina (SC). A escolha deve-se, entre outras razões, ao fato de o Estado ocupar a sétima posição nacional quanto ao número de programas de pós-graduação (PPG) e também quanto ao número de cursos de graduação presenciais. Além disso, SC expandiu a sua pós-graduação nos anos recentes, impulsionada pelas dinâmicas da interiorização da educação superior. Assim, o presente estudo foi desenvolvido por meio do uso de procedimentos e técnicas quantitativas e qualitativas, cabendo destaque para a sistematização e análise dos dados disponíveis na Plataforma Sucupira e no GeoCapes. O artigo demonstra, entre outros aspectos, que a pós-graduação catarinense cresceu mais do que a média nacional, totalizando 326\% de 1998 a 2018, mas que tal PG existe em apenas 17 das 94 IES existentes no estado. Da mesma forma, inversamente ao que ocorre com a graduação, os mestrados e doutorados são majoritariamente ofertados pelo segmento público, que concentra cerca de $70 \%$ das matrículas (53\% nas IES públicas federais e 16,6\% pela única IES estadual). Enfim, a presente pesquisa mapeou a pós-graduação catarinense, incluindo suas conquistas e limitações, de forma que seja possível tanto obter uma compreensão abrangente dos resultados de políticas públicas de educação e pesquisa do passado, quanto também inspirar iniciativas futuras.

Palavras-chave: Políticas educacionais. Educação Superior. Pós-Graduação. Santa Catarina.

Abstract: Graduate education has grown exponentially in the last decades in Brazil. Between 1998 and 2018, the National Graduate System (SNPG) grew 188\% and enrollment in masters and doctorates, 289\%. In 2017, 21,393 PhDs and 61,147 masters graduated in the country, already surpassing one of the goals of the National Education Plan for 2024: the titling of 60 thousand new masters per year. This expansion has taken place all over the country, making relevant the studies to understand the dynamics, specificities and variations between the regions, states of the federation and segments of the institutions that offer graduate programs (public and private). With this in mind, this paper analyzes the expansion of the SNPG using one state of the federation as reference: Santa Catarina (SC). Among other reasons, the choice is due to the fact that the State occupies the seventh national position in terms of the number of graduate programs (PPG) and also in the number of undergraduate courses. In addition, SC has expanded its graduate education system in recent years, driven by the dynamics of internalization of higher education. Thus, the present study was developed through the use of quantitative and qualitative techniques, with emphasis on the systematization and analysis of data available on the Sucupira Platform and GeoCapes. The article shows, among other aspects, that graduate education in Santa Catarina overgrew the national average, totaling $326 \%$ from 1998 to 2018 . In spite of that, the programs are distributed in only 17 of the 94 HEIs in the state. Likewise, in contrast to undergraduate courses, masters and doctorates are mostly offered by the public segment, which concentrates about $70 \%$ of enrollments (53\% in federal public HEIs and $16.6 \%$ in the only state HEI). Finally, this research mapped the Santa Catarina graduate education system, including its achievements and limitations, so that it is possible both to obtain a comprehensive understanding of the results of past public policies of education and research, and to inspire future initiatives.

Keywords: Educational policies. College education. Graduate Education. Santa Catarina.

- Recebido em: 13 de julho de 2019 • Aprovado em: 1 de março de 2020

DOI: http://dx.doi.org/10.1590/S1414-407720200001000010

Este é um artigo publicado em acesso aberto sob uma licença Creative Commons

https://creativecommons.org/licenses/by-nc/4.0/

Avaliação, Campinas; Sorocaba, SP, v. 25, n. 01, p. 178-198, mar. 2020 


\section{Introdução}

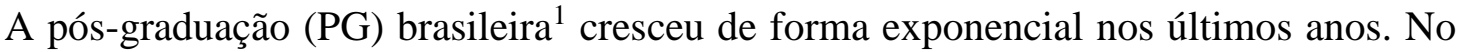
início de 1985 existiam apenas 752 cursos de mestrado e 320 de doutorado no Brasil ${ }^{2}$, sendo esse um dos motivos para que mais de $40 \%$ dos doutores brasileiros titulados até aquele ano tivessem obtido seus doutorados em instituições estrangeiras (MARCHELLI, 2005). Trinta e três anos depois, ao final de 2018, o número de cursos de pós-graduação saltou para $6.584^{3}$ (3.554 mestrados acadêmicos, 787 mestrados profissionais, 2.242 doutorados acadêmicos e um doutorado profissional), distribuídos em 4.430 programas ofertados por cerca de 450 instituições de ensino superior (IES). Nos últimos vinte anos, entre 1998 e 2018, o crescimento do número de cursos no país foi de $188 \%$, e o do número de discentes matriculados foi de $289 \%$. Como reflexo deste desenvolvimento, no ano de 2017 o Brasil titulou 21.393 doutores e 61.147 mestres. Da mesma foram, o número de estudantes bolsistas de pós-graduação também cresceu. Em 1998, a CAPES concedia 21.083 bolsas de mestrado e doutorado, mas em 2018 esse número chegou a 92.008, aos quais se somam 7.075 bolsas de pós-doutorado (CAPES, 2018; 2019a; 2019b)

No entanto, a expansão dos cursos, matrículas e bolsas não se deu de forma homogênea e simétrica. Do ponto de vista geográfico, entre 1998 a 2018, a região Norte foi a que mais expandiu (626\%), seguida pelas regiões Centro-Oeste (391\%), Nordeste (340\%), Sul (318\%) e Sudeste (104\%) (CAPES, 2019b). Contudo, ainda que esses percentuais indiquem uma significativa redução de assimetrias, os percentuais absolutos mostram que o crescimento em algumas regiões ainda está aquém do que se poderia desejar. A região Norte, por exemplo, passou de 46 (1998) para 334 cursos (2018), e mesmo que sua taxa de crescimento tenha sido seis vezes maior do que a da região Sudeste, há de se considerar que esta última subiu de 1.515 para 3.090 cursos no mesmo período: cerca de 10 vezes mais cursos do que no Norte. Observase, também, uma distribuição desigual entre os segmentos institucionais. De acordo com os dados da Avaliação Quadrienal de 2017 (referente ao período avaliativo de 2013 a 2016), 82\%

${ }^{1}$ O termo pós-graduação será utilizado, neste artigo, em seu sentido stricto sensu, ou seja, para referir-se exclusivamente aos cursos de mestrado e doutorado.

2 Dados relativos aos PPG estão disponíveis na Plataforma Sucupira e no GeoCapes, mas existe divergência de informações entre os dois sistemas. Após análise dos dados, identificou-se que o GeoCapes não contabiliza alguns programas e cursos, em especial aqueles que se encontram em processo de desativação (PPG ainda em funcionamento, mas que não aceitam novos alunos). Por essa razão, a base de dados da Plataforma Sucupira será utilizada nesta pesquisa como fonte principal de informações sobre a pós-graduação brasileira.

3 Ao contabilizar os cursos e programas, consideramos todos os que estiveram em funcionamento em algum momento do ano de referência, inclusive aqueles que iniciaram ou encerraram suas atividades ao longo ano. 
dos PPG eram ofertados por instituições públicas (58\% federais, $23 \%$ estaduais e $1 \%$ municipais) e 18\% por instituições comunitárias e privadas (BARATA, 2017).

A despeito de sua abrangência e dimensões, a expansão está longe de ser um fenômeno homogêneo em termos regionais e intrarregionais. As políticas nacionais de pós-graduação não foram apropriadas da mesma maneira. As variações são significativas e elas decorrem, ainda que não exclusivamente, da estrutura e do perfil das IES (instituições de educação superior) de cada Estado e região. As especificidades e as assimetrias do processo de expansão da pósgraduação precisam ser também compreendidas a partir das características e dos estágios de desenvolvimento e consolidação das instituições que implantam os PPG (CAPES, 2010).

Tendo isso presente, este artigo propõe investigar a expansão da PG no Brasil a partir de uma unidade da federação, o Estado de Santa Catarina (SC). A escolha deve-se a distintas razões, entre as quais o fato de SC ocupar a $7^{\mathrm{a}}$ posição nacional tanto no número de PPG quanto no de cursos de graduação presenciais. Além disso, o estado também comemorou, em 2019, o cinquentenário do seu primeiro curso de PG (mestrado em Engenharia Mecânica), implantado em 1969 pela Universidade Federal de Santa Catarina (2019). As cinco décadas oferecem elementos suficientes para um estudo longitudinal, que visa identificar relações, continuidades, dinâmicas e tendências. Trata-se de uma pesquisa oportuna e relevante na medida em que permite compreender a PG a partir das próprias dinâmicas da expansão da educação superior neste espaço-tempo.

O presente artigo decorre de uma extensa pesquisa desenvolvida entre agosto de 2016 a julho de 2019 sobre o desenvolvimento da educação superior em SC (DE BASTIANI, 2017; DE BASTIANI; TREVISOL, 2018; DE BASTIANI; TREVISOL; PEGORADO, 2018). A pesquisa documental e quantitativa sobre o surgimento das IES catarinenses, assim como sobre as dinâmicas do atual sistema catarinense de educação superior, criou condições para o presente estudo, especialmente quando aliada a indicadores sistematizados a partir das bases de dados disponíveis na Plataforma Sucupira e no GeoCapes.

\section{A educação superior em Santa Catarina}

A despeito de ser um estado pequeno, com território e população correspondentes a, respectivamente, $20^{\mathrm{a}}$ (95 $\left.346 \mathrm{~km}^{2}\right)$ e $11^{\mathrm{a}}$ (7.001.161 habitantes) posições nacionais, a educação superior catarinense respondia, em 2017, pela $7^{\mathrm{a}}$ colocação tanto quanto ao número de cursos presenciais de graduação no país quanto ao número de PPG (IBGE, 2017; DE BASTIANI; TREVISOL; PEGORARO, 2018; CAPES, 2019b). Similar ao que ocorreu na maioria dos 
estados brasileiros, a expansão se deu nas últimas décadas, particularmente a partir da aprovação da Lei 9.394/96 (LDBEN).

A primeira IES catarinense data de 1917, instalada na cidade de Florianópolis (o Instituto Politécnico). As primeiras universidades foram criadas anos depois, na década de 1960 (a Universidade Federal de Santa Catarina, em 1960, e a Universidade do Estado de Santa Catarina, em 1965). As duas décadas seguintes, correspondentes ao período da ditadura civilmilitar, nenhuma universidade foi instalada no Estado. Foram criados apenas alguns cursos superiores nas principais cidades do interior, organizados em torno das chamadas fundações educacionais de direito privado ${ }^{4}$ (FRANTZ, 2004; PEGORARO, 2006), cujo crescimento foi exponencial. No período entre 1964 e 1986 foram criadas 21 fundações, sendo 20 instituídas pelo poder público municipal e uma (a FESC) pelo legislativo estadual. A retomada do processo de criação de novas universidades se deu a partir da segunda metade dos anos 80, capitaneado pelas fundações educacionais de direito privado (IES comunitárias). Entre 1986 e 2009 foram criadas treze universidades comunitárias (privadas sem fins lucrativos) nas principais regiões do Estado (MUNIZ, 2006; PEGORARO, 2013; TREVISOL, 2015a; 2015b) 5 .

Esse último período concentrou a maior expansão no número de IES em Santa Catarina. Em 1996, por exemplo, o estado contava com 21 instituições de ensino superior, número que subiu para 94 em 2004. Esse desempenho foi cerca de três vezes maior que o ocorrido em âmbito nacional, e mais de duas vezes superior ao verificado na região Sul do país (MEC/INEP/DEAES, 2006). O ano de 2003 foi particularmente ilustrativo, pois Santa Catarina contava com 81 IES, saltando para 94 em 2004. O crescimento observado em apenas um ano foi de $16 \%$, praticamente o dobro do crescimento médio nacional (MEC/INEP, 2015, p. 28).

O crescimento das matrículas de graduação (presenciais e a distância) foi, por conseguinte, expressivo. De 47.926, em 1991, saltou para 331.350, em 2016, sendo 230.267

\footnotetext{
${ }^{4}$ Trata-se de uma modalidade específica de fundações educacionais, criadas pelo poder público municipal, porém de direito privado, definidas como IES filantrópicas e sem fins lucrativos. Inserem-se no arco das entidades do "terceiro setor" na medida em que são públicas não-estatais, cuja finalidade principal é promover atividades sem fins lucrativos, de interesse público.

${ }^{5}$ No período foram criadas as seguintes instituições de ensino superior: Universidade Regional de Blumenau (1986), Universidade do Vale do Itajaí (1989), Universidade do Sul de Santa Catarina (1989), Universidade do Oeste de Santa Catarina (1995), Universidade da Região de Joinville (1996), Universidade do Contestado (1997) Universidade do Extremo Sul Catarinense (1997), Universidade do Planalto Catarinense (1999), Centro Universitário de Jaraguá do Sul (2000), Universidade da Região do Alto Vale do Itajaí (2001), Universidade Comunitária Regional de Chapecó (2002), Centro Universitário de Brusque (2003), Universidade do Alto Vale do Rio do Peixe (2009). Atualmente a UNERJ vem sendo administrada pela PUC/PR e assume o nome de Católica de Santa Catarina, passando a ser também Centro Universitário e não mais Universidade, mantém, ainda, o mesmo órgão como mantenedora, a Fundação Educacional Regional Jaraguaense.
} 
presenciais e 101.083 a distância (MEC/INEP/DEAES, 2006; MEC/INEP, 2016, 2017; DE BASTIANI; TREVISOL, 2018).

As instituições privadas (com e sem fins lucrativos) respondiam, em 2016, por $94 \%$ do total das IES (MEC/INEP, 2016, 2017, 2018a, 2018b, 2018c). Das 94 IES, 88 eram privadas (sendo 54 instituições sem fins lucrativos e 34 com fins lucrativos) e 6 públicas (UFSC, UFFS, IFSC e IFC, UDESC e Faculdade Municipal de São José). No que tange à organização acadêmica, a maioria das IES catarinenses define-se como "faculdades" (73\%). Os centros universitários somam 11\%; as universidades, 14\% e os institutos federais, 2\% (MEC/INEP, 2016, 2017, 2018a, 2018b, 2018c).

O setor privado é também hegemônico na oferta de cursos de graduação a distância (EaD) em SC. Das 27 IES ofertantes em 2016, 24 eram privadas, sendo 12 instituições com fins lucrativos e 12 sem fins lucrativos (INEP/MEC, 2016, 2017, 2018a, 2018b, 2018c). Apenas 03 IES públicas ofertavam cursos de graduação EaD em 2016 (UFSC, IFSC e UDESC) (DE BASTIANI; TREVISOL, 2018).

O estado de Santa Catarina, diferentemente de outras unidades da federação, fez clara opção por políticas privatizantes de educação superior. O modelo fundacional foi impulsionado desde os anos 60 com o propósito de viabilizar o acesso via financiamento privado. Ao fazê-lo, o poder público retirou de si a responsabilidade pela oferta da gratuidade. Do total de estudantes matriculados em cursos de graduação em 2016 (331.350), o setor privado respondia por 77,3\% e o setor público por 22,7\% (MEC/INEP, 2016; DE BASTIANI; TREVISOL, 2018). A educação a distância é, majoritariamente, privada. Do total de matrículas em 2016 (101.083 matriculas), 97,9\% estavam em IES privadas.

As IES privadas sem fins lucrativos (comunitárias), respondem por 58\% do total das matrículas (133.844 matrículas). As instituições com fins lucrativos representam $21 \%$ e as públicas, $21 \%$ (estadual $(4,8 \%)$, federal $(15,8 \%)$ e municipal em torno de 0,4\%) (DE BASTIANI; TREVISOL, 2018).

Em 2016, as matrículas presenciais representavam 69,5\% do total (331.350). Considerando o período de 2005-2016, as matrículas presenciais cresceram 18,5\%, enquanto as de $\mathrm{EaD}, 512,9 \%$, passando de 16.492 para 101.083 (DE BASTIANI; TREVISOL, 2018). 


\section{A Pós-graduação em Santa Catarina}

A PG catarinense completou, em 2019, 50 anos de existência. Os dois primeiros cursos de mestrado foram criados em 1969 pela Universidade Federal de Santa Catarina (UFSC), nas áreas de Engenharia Mecânica e de Produção, sendo que este último foi desativado no ano de 2002. O primeiro curso de doutorado no Estado também foi implantado pela UFSC em 1981, na área de Engenharia Mecânica. Até 1995 a UFSC era a única IES a ofertar PPG, totalizando, neste ano, 33 programas.

A interiorização foi se dando de forma lenta, tendo seu início em 1995 com a criação do primeiro curso de mestrado fora da capital, na cidade de Itajaí, na área de Ciência Jurídica (UNIVALI). O primeiro doutorado no interior foi implantado doze anos depois, em 2007, também na cidade de Itajaí, na área de Administração (UNIVALI).

A Tabela 1 detalha o processo de interiorização da PG catarinense, com ênfase no ano da criação do primeiro curso de mestrado e de doutorado em cada região do Estado (Grande Florianópolis, Vale do Itajaí, Serrana, Oeste, Sul e Norte).

Tabela 1 - Ano de instalação do primeiro curso de mestrado e de doutorado em cada uma das cinco grandes regiões de Santa Catarina

\begin{tabular}{|c|c|c|c|c|}
\hline Mesorregião & Município & Curso & IES & Início \\
\hline \multicolumn{5}{|c|}{ NÍVEL MESTRADO } \\
\hline $\begin{array}{c}\text { Grande } \\
\text { Florianópolis }\end{array}$ & Florianópolis & Engenharia Mecânica & UFSC & 1969 \\
\hline Vale do Itajaí & Itajaí & Ciência Jurídica & UNIVALI & 1995 \\
\hline Serrana & Lages & Ciências do Solo & UDESC & 1997 \\
\hline Norte & Joinville & Saúde e Meio Ambiente & UNIVILLE & 1999 \\
\hline Sul & Criciúma & Ciências Ambientais & UNESC & 2001 \\
\hline Oeste & Chapecó & Ciências Ambientais & UNOCHAPECÓ & 2005 \\
\hline \multicolumn{5}{|c|}{ NÍVEL DOUTORADO } \\
\hline $\begin{array}{c}\text { Grande } \\
\text { Florianópolis }\end{array}$ & Florianópolis & Engenharia Mecânica & UFSC & 1981 \\
\hline Vale do Itajaí & Itajaí & Administração & UNIVALI & 2007 \\
\hline Sul & Criciúma & Ciências da Saúde & UNESC & 2007 \\
\hline Serrana & Lages & Ciência do Solo & UDESC & 2008 \\
\hline Norte & Joinville & Saúde e Meio Ambiente & UNIVILLE & 2014 \\
\hline Oeste & Chapecó & Ciências da Saúde & UNOCHAPECÓ & 2017 \\
\hline
\end{tabular}

Fonte: Tabela elaborada com base nos dados disponíveis na Plataforma Sucupira, consulta em março de 2019.

A despeito da interiorização impulsionada nos últimos anos, a UFSC continua respondendo pela maioria dos PPG. Em 2018, a instituição respondia por 42,4\% dos cursos de mestrado e por $65 \%$ dos de doutorado. Conforme demonstra a Tabela 2, em 2018 Santa Catarina 
contava com 260 cursos de pós-graduação, sendo 177 mestrados (134 acadêmicos e 43 profissionais) e 83 doutorados (CAPES, 2019b).

Tabela 2 - Número de cursos de PG em Santa Catarina, por IES e categoria administrativa, a partir de dados consolidados de 2018

\begin{tabular}{|c|c|c|c|c|c|}
\hline $\begin{array}{c}\text { Categoria } \\
\text { Administrativa } \\
\end{array}$ & IES & Sigla & $\begin{array}{l}\text { Mestrados } \\
\text { Acadêmicos }\end{array}$ & \begin{tabular}{c|} 
Mestrados \\
Profissionais \\
\end{tabular} & Doutorado \\
\hline \multirow{4}{*}{$\begin{array}{l}\text { Pública } \\
\text { Federal }\end{array}$} & $\begin{array}{c}\text { Universidade Federal de } \\
\text { Santa Catarina }\end{array}$ & UFSC & 62 & 13 & 54 \\
\hline & $\begin{array}{l}\text { Universidade Federal da } \\
\text { Fronteira Sul }\end{array}$ & UFFS** & 4 & 0 & 0 \\
\hline & $\begin{array}{c}\text { Instituto Federal de } \\
\text { Educação, Ciência e } \\
\text { Tecnologia Catarinense }\end{array}$ & IFC & 0 & 1 & 0 \\
\hline & $\begin{array}{c}\text { Instituto Federal de } \\
\text { Educação, Ciência e } \\
\text { Tecnologia de Santa } \\
\text { Catarina }\end{array}$ & IFSC & 0 & 4 & 0 \\
\hline $\begin{array}{l}\text { Pública } \\
\text { Estadual }\end{array}$ & $\begin{array}{c}\text { Universidade do Estado } \\
\text { de Santa Catarina }\end{array}$ & UDESC & 23 & 8 & 12 \\
\hline \multirow{12}{*}{$\begin{array}{c}\text { Privada sem } \\
\text { fins lucrativos }\end{array}$} & $\begin{array}{l}\text { Universidade Regional de } \\
\text { Blumenau }\end{array}$ & FURB & 9 & 2 & 3 \\
\hline & $\begin{array}{c}\text { Universidade Alto Vale } \\
\text { do Rio do Peixe }\end{array}$ & UNIARP & 1 & 1 & 0 \\
\hline & $\begin{array}{l}\text { Universidade Comunitária } \\
\text { da Região de Chapecó }\end{array}$ & UNOCHAPECÓ & 5 & 2 & 1 \\
\hline & $\begin{array}{l}\text { Universidade da Região } \\
\text { de Joinville }\end{array}$ & UNIVILLE & 4 & 1 & 1 \\
\hline & $\begin{array}{l}\text { Universidade do } \\
\text { Contestado }\end{array}$ & UNC & 1 & 1 & 0 \\
\hline & $\begin{array}{c}\text { Universidade do Extremo } \\
\text { Sul Catarinense }\end{array}$ & UNESC & 6 & 1 & 2 \\
\hline & $\begin{array}{c}\text { Universidade do Oeste de } \\
\text { Santa Catarina }\end{array}$ & UNOESC & 5 & 1 & 2 \\
\hline & $\begin{array}{c}\text { Universidade do Planalto } \\
\text { Catarinense }\end{array}$ & UNIPLAC & 2 & 0 & 0 \\
\hline & $\begin{array}{l}\text { Universidade do Sul de } \\
\text { Santa Catarina }\end{array}$ & UNISUL & 5 & 0 & 2 \\
\hline & $\begin{array}{l}\text { Universidade do Vale do } \\
\text { Itajaí }\end{array}$ & UNIVALI & 7 & 4 & 6 \\
\hline & $\begin{array}{c}\text { Universidade Sociedade } \\
\text { Educacional de Santa } \\
\text { Catarina }\end{array}$ & UNISOCIESC & 0 & 2 & 0 \\
\hline & Faculdade SATC & FASATC & 0 & 1 & 0 \\
\hline $\begin{array}{c}\text { Privada com } \\
\text { fins lucrativos }\end{array}$ & $\begin{array}{c}\text { Centro Universitário } \\
\text { FACVEST }\end{array}$ & FACVEST & 0 & 1 & 0 \\
\hline TOTAL & & & 134 & 43 & 83 \\
\hline
\end{tabular}

Fonte: Tabela elaborada pelos autores com base nos dados disponíveis na Plataforma Sucupira.

* As categorias aqui apresentadas seguem o que é considerado pela LDB. No E-MEC online, a FURB e a UNIARP encontram-se categorizadas como IES públicas municipais.

**Apenas estão apresentados nesta tabela os cursos oferecidos em Santa Catarina. A UFFS possui outros cursos ofertados no Paraná e no Rio Grande do Sul. Ainda, não consta neste quadro o Mestrado Profissional em Matemática (PROFMAT), que é oferecido no campus Chapecó, pois o campus é apenas um dos polos da rede. 
A Tabela 3 evidencia a distribuição dos cursos de PG, por categoria administrativa, entre as cinco grandes regiões de Santa Catarina. Observa-se uma grande concentração na Grande Florianópolis (57\%), seguida pelas regiões do Vale do Itajaí (12\%), do Oeste (10,5\%), do Norte $(8,6 \%)$, do Sul $(6,5 \%)$ e Serrana $(5,4 \%)$.

Tabela 3 - Distribuição dos cursos de mestrado e doutorado pelas cinco regiões de Santa Catarina, por segmento institucional, em 2018

\begin{tabular}{r|c|c|c|c|c|c}
\hline CATEGORIAS / REGIÕES & $\begin{array}{c}\text { Grande } \\
\text { Florianópolis }\end{array}$ & $\begin{array}{c}\text { Vale do } \\
\text { Itajaí }\end{array}$ & Oeste & Norte & Sul & Serrana \\
\hline Públicas Federais & 134 & 04 & 09 & 03 & 03 & 01 \\
\hline Públicas Estaduais & 24 & & 03 & 12 & & 10 \\
\hline Privadas sem fins lucrativos & 03 & 30 & 17 & 09 & 15 & 03 \\
\hline Privadas com fins lucrativos & - & - & - & - & - & 01 \\
\hline TOTAL \% & $\mathbf{5 7 \%}$ & $\mathbf{1 2 \%}$ & $\mathbf{1 0 , 5 \%}$ & $\mathbf{8 , 6 \%}$ & $\mathbf{6 , 5 \%}$ & $\mathbf{5 , 4 \%}$ \\
\hline
\end{tabular}

Fonte: Tabela elaborada pelos autores a partir de: MEC/INEP, 2016; DE BASTIANI, TREVISOL, 2018; Plataforma Sucupira, 2019.

No mapa a seguir é possível visualizar a distribuição dos cursos de PG nas diferentes cidades do Estado. Como é possível observar, do total dos municípios catarinenses em 2018 (295 ao todo), dezenove ${ }^{6}$ sediavam cursos de mestrado e nove ${ }^{7}$ de doutorado. Na Grande Florianópolis, os PPG se concentravam nas cidades de Florianópolis e Palhoça. No Vale do Itajaí, nas cidades de Blumenau e Itajaí. Na região Norte, nas cidades de Joinville, Canoinhas, Mafra e Araquari. Na região Sul, há cursos em Criciúma, Tubarão e Araranguá. Na região Serrana os cursos concentram-se em Lages e Curitibanos. E, por fim, na região Oeste, nas cidades de Caçador, Chapecó, Concórdia, Joaçaba, Pinhalzinho, Videira e Xanxerê.

\footnotetext{
${ }^{6}$ Em 2018 havia cursos de mestrado implantados nos municípios de Florianópolis, Joinville, Chapecó, Blumenau, Itajaí, Criciúma, Lages, Tubarão, Araranguá, Caçador, Joaçaba, Araquari, Canoinhas, Concórdia, Curitibanos, Palhoça, Pinhalzinho, Videira e Xanxerê (ordem decrescente de número de cursos).

${ }^{7}$ As seguintes cidades catarinenses dispunham de cursos de doutorado em 2018: Florianópolis, Itajaí, Blumenau, Lages, Chapecó, Criciúma, Joinville, Tubarão e Joaçaba (ordem decrescente de número de cursos).
} 
Figura 1 - Mapa da distribuição dos cursos de Pós-Graduação em Santa Catarina, por município, em 2018

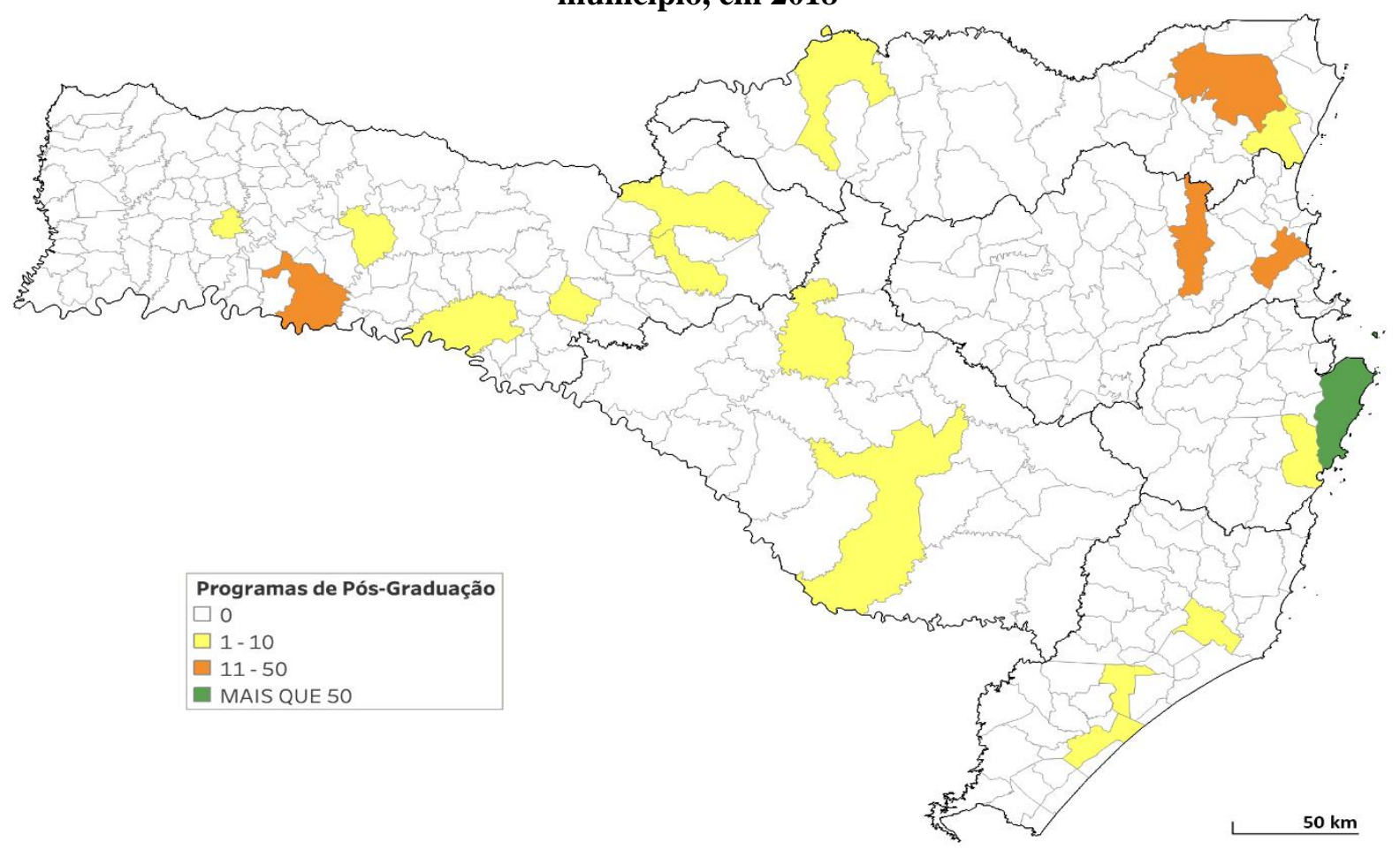

Fonte: Mapa elaborado pelos autores a partir da base de dados da Plataforma Sucupira (2019) e IBGE (2017).

A interiorização da pós-graduação em SC é recente, decorrente do fato da educação superior ser, também, muito jovem. Das 18 IES que ofertam PPG, 11\% sugiram na década de $60^{8} ; 5,5 \%$ na década de $70^{9} ; 16,5 \%$ na década de $80^{10} ; 28 \%$ na década de $90^{11}$ e, $39 \%$, nos anos $2000^{12}$. O pico da expansão das IES no Estado se deu logo após a aprovação da LDBEN. Entre 1996 e 2004 o número de IES em SC cresceu 347,6\%, passando de 21, em 1996, para 94, em 2004. (MEC/INEP/DEAES, 2006, p. 31). A grande maioria dos PPG nas cidades do interior foram recomendados pela CAPES a partir de 2005.

\footnotetext{
${ }^{8}$ Na década de 60 do século passado foram criadas a Universidade Federal de Santa Catarina (1960) e a Universidade do Estado de Santa Catarina (1965).

${ }^{9} \mathrm{Na}$ década de 70 foi criada a UNISOCIESC (1971).

${ }^{10} \mathrm{Na}$ década de 80 foram criadas a Universidade Regional de Blumenau (1986), a Universidade do Vale do Itajaí (1989) e a Universidade do Sul de Santa Catarina (1989).

${ }^{11}$ Na década de 90 surgiram a Universidade do Oeste de Santa Catarina (1995), a Universidade da Região de Joinville (1996), a Universidade do Contestado (1997), a Universidade do Extremo Sul de Santa Catarina (1997) e a Universidade do Planalto Catarinense (1999).

12 Na primeira década do século XXI, surgiram o Centro Universitário FACVEST (2001), a Universidade Comunitária da Região de Chapecó (2002), a Faculdade SATC (2003), o Instituto Federal de Santa Catarina (2008), o Instituto Federal Catarinense (2008), Universidade Federal da Fronteira Sul (2009) e a Universidade do Alto Vale do Rio do Peixe (2009).
} 
A expansão da PG guarda, portanto, uma relação estreita com as políticas de expansão impulsionadas pelo PROUNI (Programa Universidade para Todos) e pelo REUNI (Programa de Apoio a Planos de Reestruturação e Expansão das Universidades Federais). Em 2003, no que tange às IES públicas, a UDESC (única universidade estadual) aprovou a implantação do Centro de Educação Superior do Oeste. Alguns anos depois, em 2008, foram criados o Instituto Federal de Educação, Ciência e Tecnologia de Santa Catarina (IFSC) e o Instituto Federal de Educação, Ciência e Tecnologia Catarinense (IFC). No ano seguinte, em 2009, a UFSC aprovou a criação dos seus três primeiros campi fora da capital, nas cidades Araranguá, Joinville e Curitibanos. Nesse mesmo ano foi criada a segunda universidade federal no Estado, a Universidade Federal da Fronteira Sul (UFFS).

O Gráfico 1 evidencia o processo de expansão da PG catarinense. O crescimento do número de cursos nos últimos vinte anos (1998-2018) foi de 326\% (cerca de 16,3\% ao ano), uma média superior ao verificado a nível nacional, que foi de $188 \%$ (cerca de 9,4\% ao ano) (CAPES, 2019b). O crescimento dos cursos de doutorado no Estado (388\%) no período entre 1998 e 2018 ficou acima do mestrado (302\%).

\section{Gráfico 1 - Expansão dos cursos de mestrado e de doutorado em Santa Catarina no período} 1969-2018 ${ }^{13}$

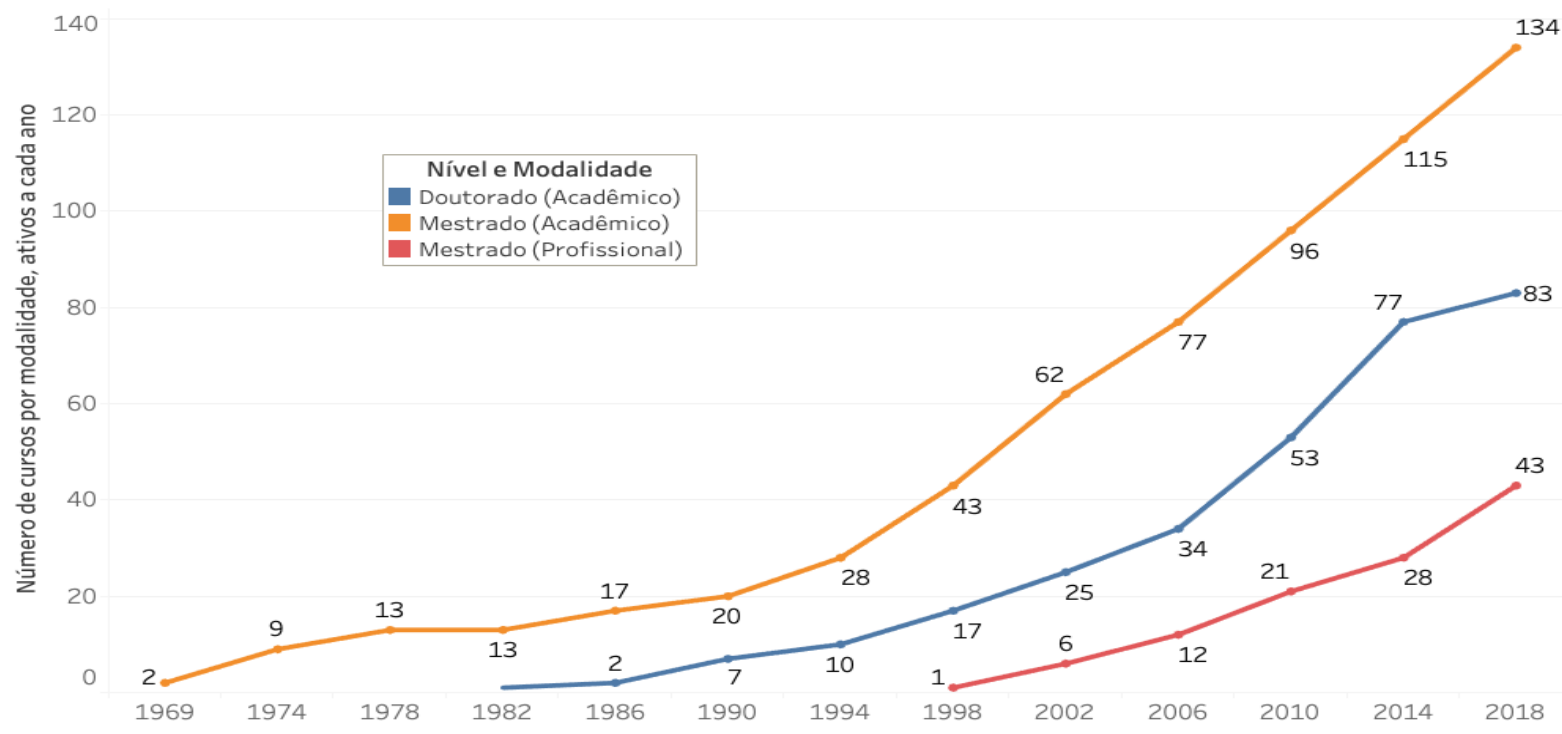

Fonte: Gráfico elaborado pelos autores a partir da base de dados disponível na Plataforma Sucupira. Acesso em: 10 jul. 2019.

${ }^{13}$ Para o cômputo final dos cursos em SC foram excluídos os PPG da UFFS ofertados nos campi situados no Rio Grande do Sul e no Paraná. 
A expansão dos cursos reflete-se, por conseguinte, no quantitativo das matrículas em todas as modalidades. O percentual de crescimento nos últimos 20 anos (1998-2018) foi de $409 \%$, correspondente a uma média de $20,4 \%$ ao ano. A modalidade profissional (mestrado) foi a que apresentou a maior taxa de expansão.

\section{Gráfico 2 - Crescimento das matrículas de mestrado e de doutorado em Santa Catarina no período 1998-2018}

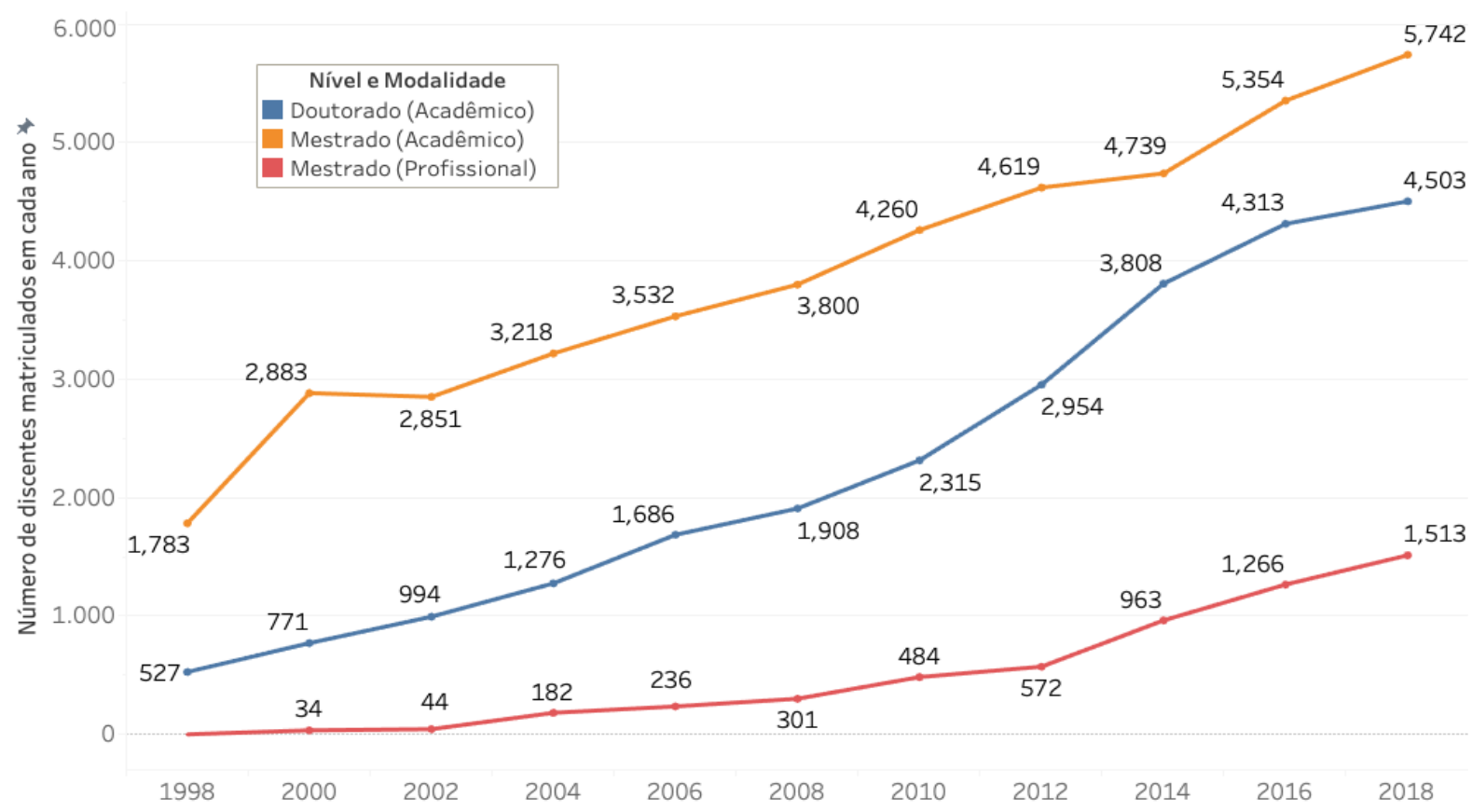

Fonte: Gráfico elaborado pelos autores a partir da base de dados disponível no GeoCapes. Acesso em: 10 jul. 2019.

O gráfico abaixo permite dimensionar a expansão das matrículas da PG em SC nos últimos anos no comparativo com a graduação. As taxas anuais de crescimento são similares, com uma ligeira vantagem para a PG. Como é possível observar no gráfico abaixo, no período entre 2000 e 2016, as matrículas dos cursos de graduação presenciais e a distância (EaD) aumentaram cerca de $180 \%$, uma média de $11,2 \%$ ao ano (de 118.329 matrículas, em 2000, para 331.350 matrículas, em 2016). A expansão das matrículas da PG no mesmo período foi de 196\%, uma média de 12,3\% ao ano (de 3.688, em 2000, para 10.933, em 2016) (CAPES, 2019b; DE BASTIANI; TREVISOL, 2018). 
Gráfico 3 - Evolução das matrículas em cursos de graduação (presenciais e a distância) e de PG em Santa Catarina (2000-2016)

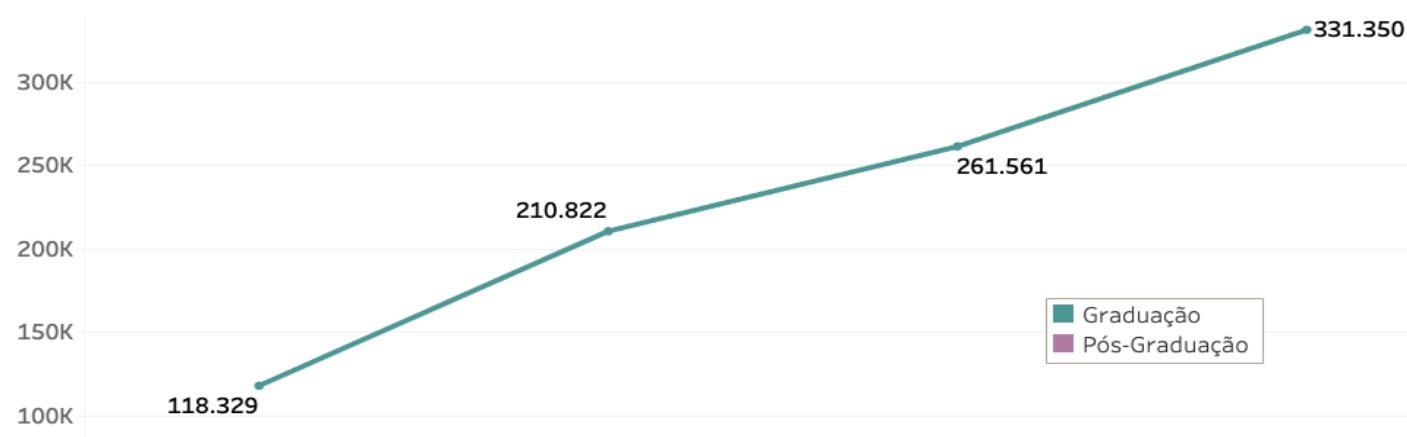

$50 \mathrm{~K}$

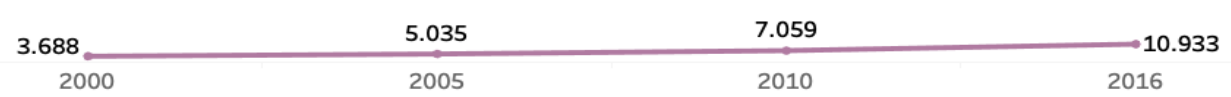

Fonte: Gráfico elaborado pelos autores com base nos dados disponíveis em: MEC/INEP/DEAES, 2006; MEC/INEP, 2016; DE BASTIANI; TREVISOL, 2018 e GeoCapes, 2019.

A expansão do número de discentes na pós-graduação tem impacto direto no número de novos mestres e doutores formados. O gráfico a seguir, referente ao período 1998-2018, evidencia uma taxa de crescimento de $493 \%$, o que corresponde a cerca de $24,6 \%$ ao ano (CAPES, 2019; CGEE, 2016). O percentual supera, inclusive, a taxa média de aumento das matrículas no período. Esse aumento representa também uma redução nas taxas de abandono ou desligamento ao longo dos anos. Em 2018, as IES catarinenses titularam 3.565 pósgraduandos: 2.649 mestres e 916 doutores (CAPES, 2019a).

Gráfico 4 - Número de mestres e doutores titulados em Santa Catarina (1998-2018)

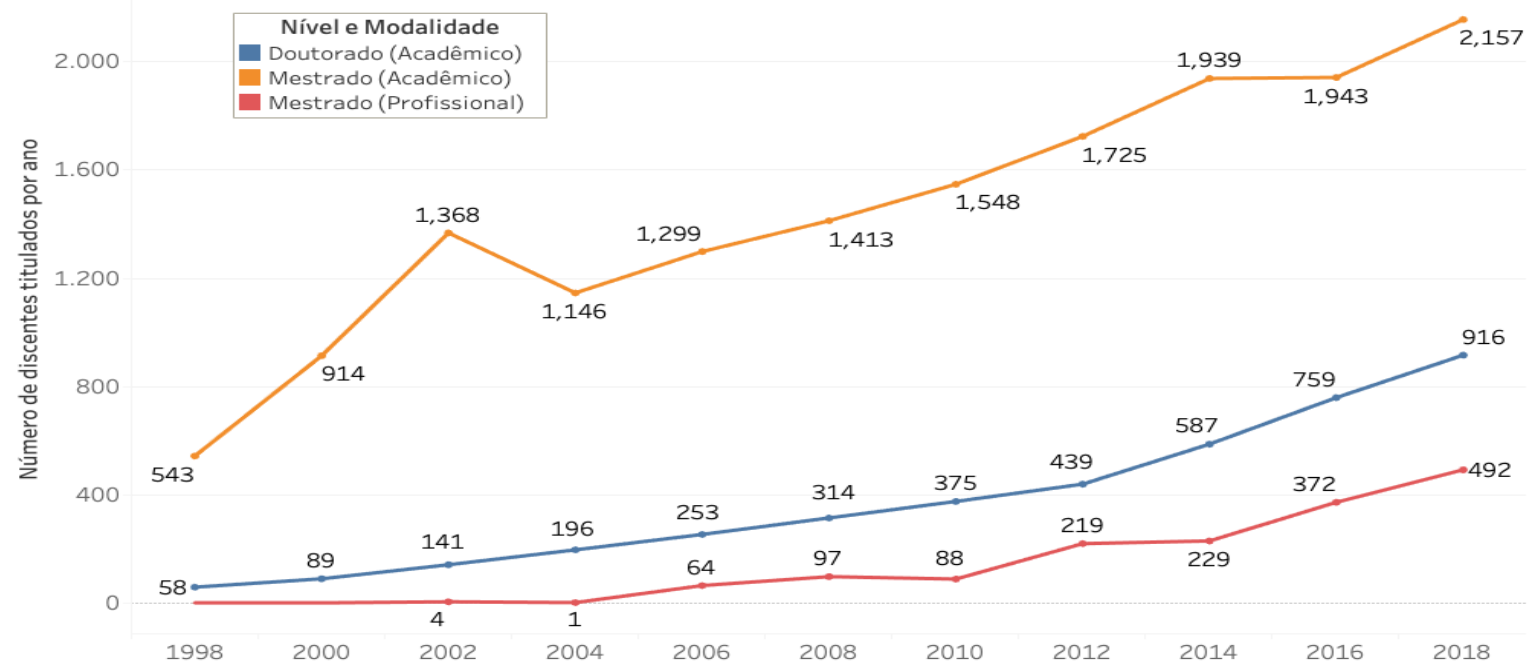

Fonte: Gráfico elaborado pelos autores a partir da base de dados disponível no GeoCapes. Acesso em: 10 jul. 2019. 
Os percentuais de matrículas e titulados também revelam aspectos interessantes quanto à natureza jurídica das IES ofertantes. A educação superior catarinense é majoritariamente privada. 94\% das IES definem-se como IES privadas com ou sem fins lucrativos. Esse segmento, por conseguinte, responde por $79 \%$ das matrículas de graduação no Estado. Os percentuais se invertem em relação à PG. As IES públicas, conforme demonstra o gráfico a seguir, respondem por $69,6 \%$ das matrículas na PG.

\section{Gráfico 5 - Distribuição das matrículas de graduação presenciais e em cursos de PG em Santa Catarina por categoria administrativa das IES, no ano de 2016}

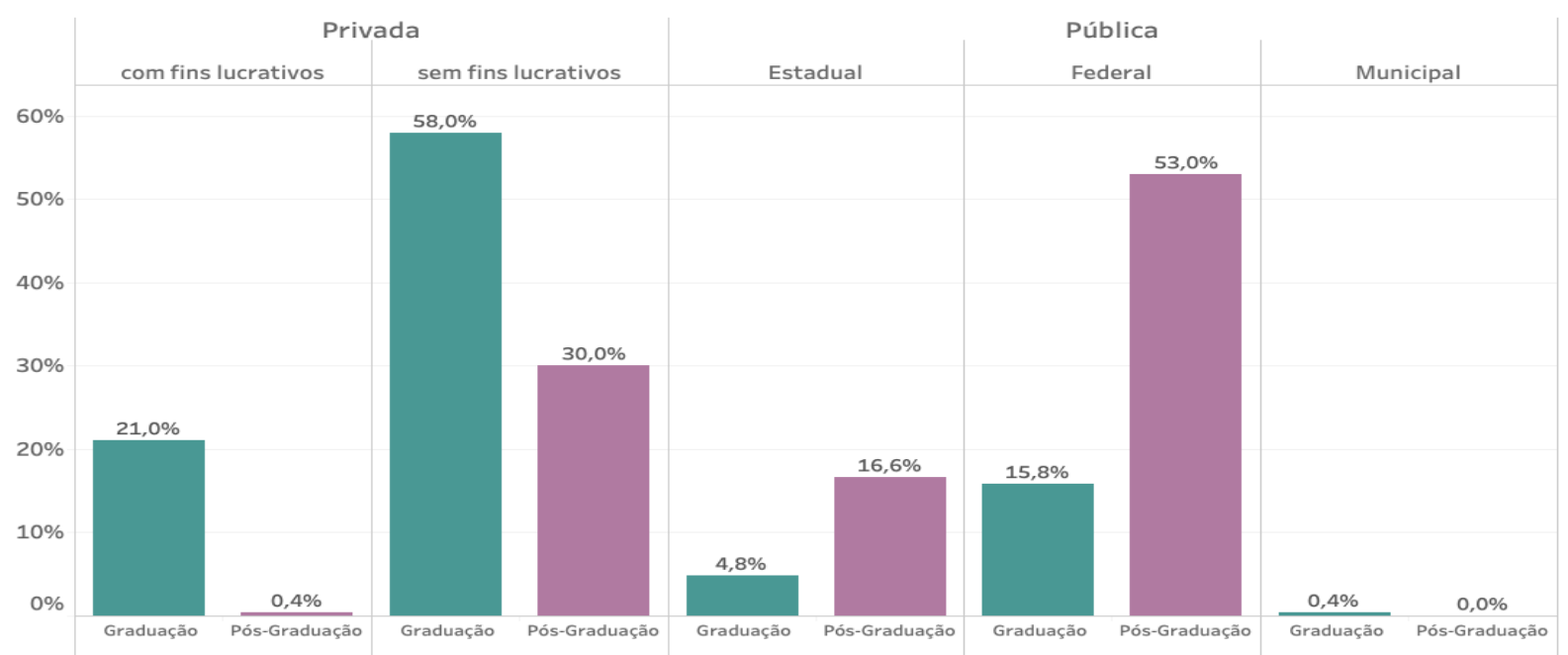

Fonte: Elaborada pelos autores a partir de: MEC/INEP, 2016; DE BASTIANI, TREVISOL, 2018; GeoCapes, 2019.

Ainda que 36\% das IES catarinenses sejam privadas com fins lucrativos, o gráfico acima evidencia que, a despeito de responderem por $21 \%$ do total de matrículas de graduação presencial, tais instituições ofertam apenas $0,4 \%$ do total de cursos de PG do Estado. De fato, do total das IES catarinenses (94 ao todo), apenas 18 ofertam PPG, sendo 5 públicas, 12 privadas sem fins lucrativos e apenas uma privada com fins lucrativos (que oferta apenas um mestrado profissional, conforme visto na Tabela 2).

Observa-se ainda que a PG no Estado é majoritariamente ofertada pelas universidades. Ao contrário do que é visto na graduação, em que as faculdades e os centros universitários respondem por $84 \%$ do total das IES ofertantes, a pós-graduação catarinense está nas universidades $(77,7 \%$ do total das IES ofertantes), seguidas pelos institutos federais $(11,1 \%)$, centro universitários $(5,5 \%)$ e faculdades $(5,5 \%)$.

Além da quantidade, as IES públicas concentram também a maior qualidade na PG do Estado, respondendo pela oferta dos programas mais bem avaliados pela Coordenação de 
Aperfeiçoamento de Pessoal de Nível Superior (CAPES). De acordo com a última avaliação realizada (Quadriênio 2013-2016), essas instituições contam com 31 dos 40 PPG nota 5 em SC (considerados muito bons). Além disso, 20 dos 21 programas de excelência (notas 6 e 7) estão na Universidade Federal de Santa Catarina, e essa distribuição de notas pode ser vista no Gráfico 6.

\section{Gráfico 6 - Avaliação dos PPG em Santa Catarina por instituições e notas obtidas na Avaliação Quadrienal da Capes (2013-2016), conforme categoria administrativa das IES}

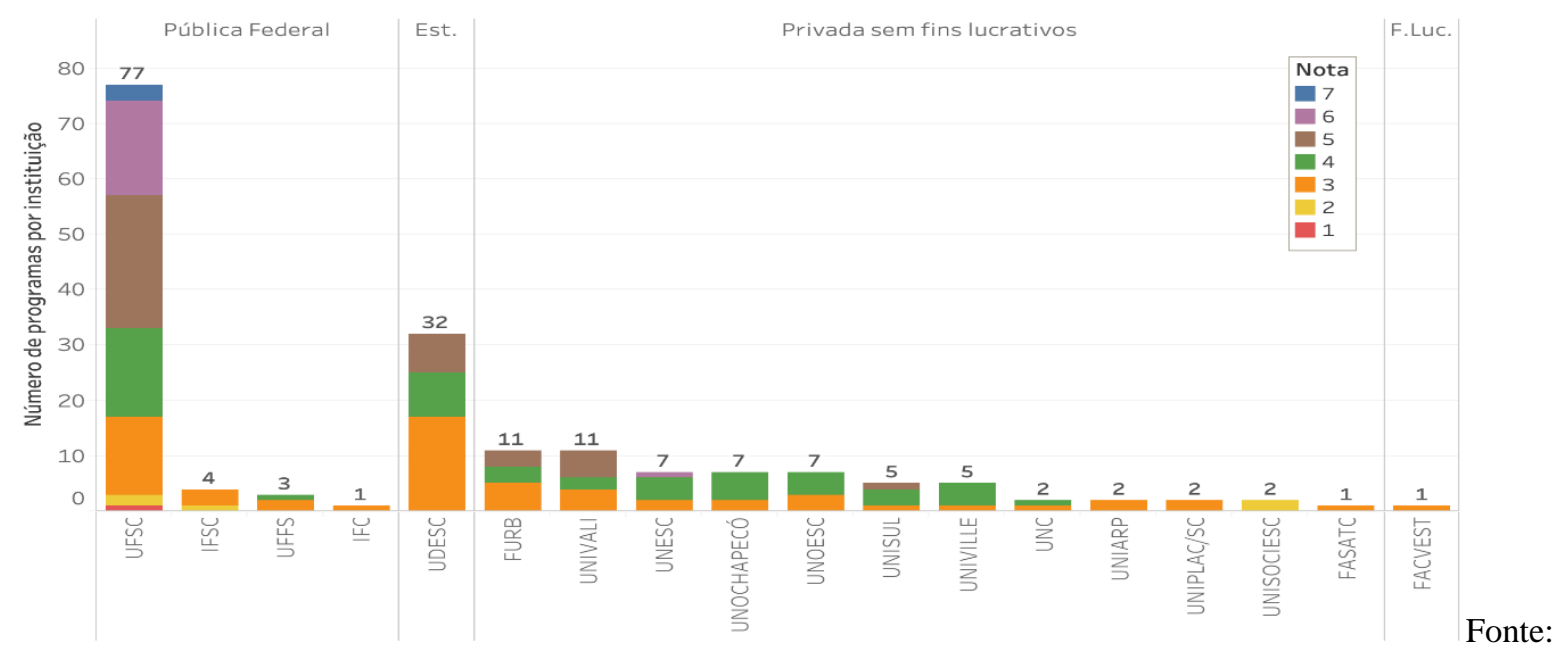

Gráfico elaborado pelos autores a partir da base de dados da Plataforma Sucupira, 2019.

Como pode ser visto, a maior parte da pós-graduação catarinense está concentrada na UFSC e na UDESC, inclusive, onde se encontra a maioria dos programas notas 5, 6 e 7 do estado. As universidades FURB, UNIVALI e UNISUL são ofertam PPG com nota 5. A UNESC é a única IES privada sem fins lucrativos que conta com um PPG nota 6 em Santa Catarina, na cidade de Criciúma.

Ainda que o agrupamento da maioria dos PPG em poucas instituições possa motivar a busca por políticas públicas de redução de assimetrias no Estado, a concentração de notas elevadas em IES mais tradicionais pode ser parcialmente explicada pelo simples processo de maturação dos programas.

A tabela a seguir evidencia a relação entre o tempo médio de existência dos programas, em anos, com as notas obtidas na última Avaliação Quadrienal da CAPES (2017). Para isso, foram contabilizados todos os programas que fizeram parte da clientela da avaliação, considerando-se a "idade" que eles tinham no dia 31 de dezembro de 2016, data de 
encerramento do ciclo avaliativo. Considerando apenas programas com notas superior a $3^{14}$, a tabela mostra uma clara relação entre o seu tempo médio de existência e as notas por eles obtidas. Conforme destaca Brasil (2018), os dados refletem uma evolução natural dos PPG, que amadurecem e se desenvolvem ao longo do tempo.

Tabela 4 - Tempo médio de existência, em anos, dos PPG no país, região Sul e em Santa Catarina, por nota ${ }^{15}$

\begin{tabular}{c|c|c|c|c|c|c|c||c}
\hline REGIÃO E NOTA & 1 & 2 & 3 & 4 & 5 & 6 & 7 & MÉDIA \\
\hline Brasil & 6,00 & 9,71 & 5,32 & 12,87 & 22,16 & 29,09 & 37,55 & $\mathbf{1 4 , 3 5}$ \\
\hline Sul & - & 6,50 & 3,85 & 11,26 & 19,28 & 27,22 & 32,74 & $\mathbf{1 2 , 7 6}$ \\
\hline \hline Santa Catarina & - & - & 3,65 & 11,3 & 18,75 & 25,22 & 30,00 & $\mathbf{1 2 , 4 7}$ \\
\hline
\end{tabular}

Fonte: BRASIL, André. Gestão de riscos na avaliação de programas de pós-graduação: estratégias para estimar o potencial de sucesso de cursos novos, com base em propostas apresentadas à CAPES. 2018. 247 p. Dissertação (Mestrado) - Instituto de Pesquisa Econômica Aplicada, Brasília, 2018. Disponível em: http://doi.org/10.6084/m9.figshare.8378363.v2. Acesso em: 1 jul. 2019..

De acordo com os dados acima, a PG catarinense se mostra mais jovem que as médias nacional e da região Sul em praticamente todos os estratos da avaliação, apresentando tempo médio de existência de 12,47 anos na última Avaliação Quadrienal. Assim, considerando que os programas de SC tendem a alcançar notas mais altas antes do que geralmente acontece no país como um todo, é de se esperar que o histograma de notas no Estado apresente uma ligeira assimetria negativa em relação ao resto do país, com concentração maior de PPG no lado direito da distribuição

14 A opção pelos estratos de nota entre 3 a 7 deve-se ao fato dos programas notas 1 e 2 estarem sujeito a descredenciamento junto ao SNPG. A presente análise se concentra nas notas 3 a 7.

${ }^{15} \mathrm{O}$ levantamento dos dados que integram esta tabela foi realizado antes da avaliação de recursos da Avaliação Quadrienal. Por essa razão, são possíveis pequenas variações na distribuição das notas. 


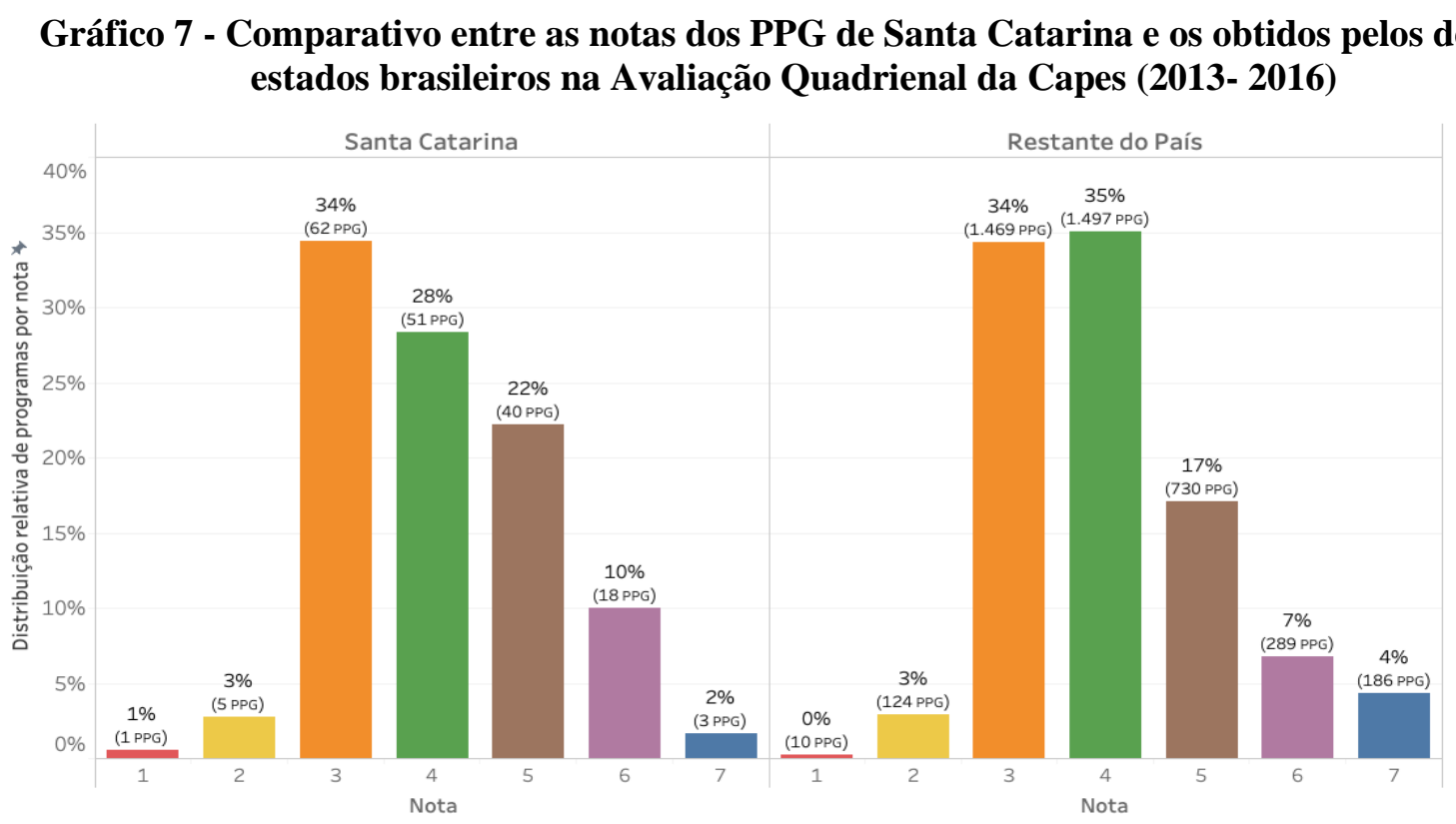

Fonte: Gráfico elaborado pelos autores a partir da base de dados da Plataforma Sucupira. Acesso em: 10 jul. 2019.

É possível observar que a distribuição de notas em Santa Catarina não é muito distante do que se observa no restante do país, inclusive com o mesmo percentual observado de PPG nota 3. Como previsto, vemos que há um deslocamento positivo de programas da nota 4 para a nota 5 (22\% em SC, contra $17 \%$ na média nacional), mas o mesmo não acontece nos programas de excelência. Embora SC tenha aproximadamente o mesmo percentual de PPG notas 6 e 7 que o restante do país, no estado existe ainda uma concentração mais elevada na nota 6 , algo que pode ser compreendido uma vez que esses programas são ainda cerca de dez anos mais jovens do que a média de programas nota 7 no resto do país.

O crescimento e o bom desempenho da pós-graduação em Santa Catarina tem uma relação direta com as políticas de fomento, sobretudo as bolsas e os recursos de capital e custeio provenientes da CAPES e da FAPESC. A título de ilustração, em 1998 o Estado recebia 5\% (687 de mestrado e 375 de doutorado) das 21.083 bolsas concedidas pela CAPES para todo o país. Em vinte anos, em 2018, esse número aumentou 281\%, chegando a um total de 4.046 bolsas: 2.100 de mestrado e 1.946 de doutorado (4,4\% do total nacional). A concessão de bolsas pela CAPES, apesar do aumento registrado ao longo dos anos, ficou aquém da demanda. Enquanto o número de bolsas cresceu $281 \%$ no período 1998-2018, as matrículas da PG cresceram 409\% (GEOCAPES, 2016; 2019). Além das bolsas da CAPES, SC conta também com um conjunto de bolsas provenientes do Programa UniEdu (FUMDES) e da Fundação de Amparo à Pesquisa e Inovação do Estado de Santa Catarina (FAPESC). A título de ilustração, em 2017, o FUMDES investiu cerca de R \$ 8.443.000,00 em bolsas de especialização e pós- 
graduação stricto sensu em IES públicas e privadas catarinenses, implementando assim 168 bolsas de mestrado e 291 de doutorado no estado (SANTA CATARINA/SED, 2017).

O estudo realizado revelou também que as IES públicas do Estado foram as que mais receberam bolsas da CAPES. Do total de bolsas concedidas em 2018 (4.046), as IES privadas ficaram com 18\% (740) e as públicas com 82\% (3.306), sendo que a maioria delas ficou concentrada na UFSC (2.702) bolsas. Apesar da grande diferença observada no que tange a categoria administrativa das IES, a distribuição em SC não difere do praticado em âmbito nacional, uma vez que cerca de $86,6 \%$ das bolsas da CAPES são destinadas às IES públicas (61,8\% para as federais e 24,8\% para as estaduais) e 13,4\%, às IES privadas (GEOCAPES, 2016, 2019).

\section{Considerações finais}

O estudo longitudinal desenvolvido permite compreender a PG a partir do contexto e do desenho institucional da educação superior em Santa Catarina. As especificidades do sistema catarinense incidiram diretamente na organização e desenvolvimento da PG. Da mesma forma, as políticas nacionais, a despeito de sua importância, foram apropriadas e implementadas a partir das dinâmicas institucionais da educação superior no Estado. Enfim, a pesquisa revelou que as variáveis locais (estadual e regionais) tiveram inegável importância no desenvolvimento da PG ao longo das décadas, mas alguns aspectos merecem destaque:

A educação superior catarinense é, em primeiro lugar, predominantemente privada. As IES com e sem fins lucrativos respondiam, em 2016, por $94 \%$ do total das instituições, por $79 \%$ das matrículas da graduação e por 30,6\% dos cursos de PG. Até 2009 (ano da criação da UFFS), SC contava com apenas duas universidades públicas (UFSC e UDESC), ambas sediadas na capital Florianópolis. A interiorização, desde 1968, foi capitaneada pelas IES sem fins lucrativos (comunitárias), por meio das fundações públicas de direito privado. A primeira IES privada com fins lucrativos foi criada em 2000.

A PG catarinense é, em segundo lugar, predominantemente pública. Inversamente ao que ocorre com a graduação, as IES públicas respondem pela oferta de $69,4 \%$ do total dos cursos de mestrado e doutorado. As duas universidades públicas mais antigas do Estado (UFSC e UDESC) respondem pela oferta de 172 cursos de mestrado e doutorado, de um total de 260. O setor privado com fins lucrativos oferta apenas um curso de mestrado (o que corresponde a 0,4\% do total) e $21 \%$ do total das matrículas de graduação no Estado. 
A pesquisa evidenciou, em terceiro lugar, a liderança exercida pela UFSC na organização e consolidação da pós-graduação catarinense. Além de ter sido pioneira na implantação do primeiro PPG em 1969, ela formou, ao longo das décadas, parte expressiva dos mestres e doutores das diferentes IES. Até 1995 a UFSC era a única IES a ofertar PPG, totalizando, neste ano, 33 programas. Em 2018, a UFSC respondia por 42,3\% do total dos cursos de mestrado e 65,7\% de doutorado do Estado. Dos 21 PPG notas 6 e 7 em SC, a UFSC responde por 20 deles. Cerca de 27,4\% dos PPG da UFSC são notas 6 e 7, sendo três deles nota 7 (Engenharia de Materiais, Engenharia Química e Química).

O estudo revelou, em quarto lugar, que a interiorização da PG é um fenômeno recente. O primeiro curso de mestrado fora da capital Florianópolis data de 1995 e o primeiro doutorado, de 2007, ambos implantados por IES privadas sem fins lucrativos (comunitárias). Esse segmento institucional foi o principal responsável pela implantação dos PPG nas cidades do interior do Estado. Em 2018, as IES comunitárias respondiam pela oferta de 30,2\% do total de PPG em SC, a quase totalidade instalados em cidades do interior do Estado.

Por fim, em quinto lugar, a expansão da PG em SC se deu em percentuais acima dos verificados em âmbito nacional, conforme evidenciado na Tabela 5. Enquanto a média nacional de crescimento de cursos de mestrado e doutorado foi de $188 \%$ no período entre 1998 e 2018 , o percentual em SC no mesmo período foi $326 \%$.

Tabela 5 - Percentuais de expansão de cursos, matrículas e titulados (M e D) em Santa Catarina (1998-2018)

\begin{tabular}{c|c|c|c}
\hline & CURSOS & $\begin{array}{c}\text { MATRÍCULAS } \\
\mathbf{1 9 9 8 - 2 0 1 8}\end{array}$ & $\begin{array}{c}\text { TITULADOS } \\
\mathbf{1 9 9 8 - 2 0 1 8}\end{array}$ \\
\hline ITENS & $\mathbf{1 9 9 8 - 2 0 1 8}$ & $409 \%(20,5 \%$ ano $)$ & $493 \%(24,7 \%$ ano $)$ \\
\hline Santa Catarina & $326 \%(16,3 \%$ ano $)$ & $289 \%(14,5 \%$ ano $)$ & $455 \%(22,8 \%$ ano $)$ \\
\hline
\end{tabular}

Fonte: Tabela elaborada pelos autores a partir de dados da Plataforma Sucupira e GeoCapes, 2019.

A investigação evidenciou, por fim, fortes assimetrias em termos regionais. A presença das duas primeiras e mais antigas universidades públicas (UFSC e UDESC) em Florianópolis produziu, como consequência, alta concentração de PPG na capital do Estado. A interiorização foi se dando de forma lenta, capitaneada pelas IES privadas sem fins lucrativos. $57 \%$ dos cursos são ofertados na região da Grande Florianópolis. A região Serrana é a que apresenta o menor percentual $(5,4 \%$ do total $)$. 


\section{Referências}

BARATA, Rita Barradas. Avaliação quadrienal 2013-2016. In: ENCONTRO NACIONAL DE PRÓ-REITORES DE PESQUISA E PÓS-GRADUAÇÃO, 33., João Pessoa, 2017. Anais [...]. João Pessoa: UFPB, 2017. Disponível em: http://www.propesq.ufpb.br/enprop. p.1-37.

BRASIL, André. Gestão de riscos na avaliação de programas de pós-graduação: estratégias para estimar o potencial de sucesso de cursos novos, com base em propostas apresentadas à CAPES. 2018. 247 p. Dissertação (Mestrado) - Instituto de Pesquisa Econômica Aplicada, Brasília, 2018. Disponível em: http://doi.org/10.6084/m9.figshare.8378363.v2. Acesso em: 1 jul. 2019.

CAPES. DPB. Diretoria de Programas e Bolsas do País. Evolução da concessão de bolsas no país (2013-2017). Brasília, 2018. Disponível em: http://www.capes.gov.br.

CAPES. GeoCapes. Indicadores: Concessão de bolsas de pós-graduação da Capes no Brasil. Dados 2016. Visão analítica. Brasília, DF, 2016. Disponível em: https://geocapes.capes.gov.br/geocapes/. Acesso em: 15 ago. 2018.

CAPES. GeoCapes. Indicadores: Concessão de bolsas de pós-graduação da Capes no Brasil. Dados 2018. Brasília, DF, 2019a. Visão analítica. Disponível em: https://geocapes.capes.gov.br/geocapes/. Acesso em: 15 jun. 2019.

CAPES. Plano Nacional de Pós-Graduação 2011-2020. Brasília, DF, 2010. v. I e II.

CAPES. Plataforma Sucupira. Dados e estatísticas. Brasília, DF, 2019b. Disponível em: https://sucupira.capes.gov.br/sucupira/. Acesso em: jun. 2019.

DE BASTIANI, Sherlon Cristina. Dinâmicas de desenvolvimento da educação superior na região Oeste de Santa Catarina (1968-2015). 2017. 119 p. Dissertação (Mestrado) Universidade Federal da Fronteira Sul, Chapecó, SC, 2017.

DE BASTIANI, Sherlon Cristina; TREVISOL, Joviles. Vitório. A expansão da educação superior presencial em Santa Catarina (1990-2016). Revista Internacional de Educação Superior, Campinas, v. 4, n. 3, p. 558-579, set./dez. 2018.

DE BASTIANI, Sherlon Cristina; TREVISOL, Joviles Vitório; PEGORARO, Ludimar. A educação superior em SantaCatarina: um século de história (1917-2017). EccoS, Revista Científica, São Paulo, n. 47, p. 375-395 set./dez. 2018.

FRANTZ, Walter. Universidade comunitária: uma iniciativa pública não-estatal em construção. Ijuí: Editora Unijuí, 2004. Cadernos Unijuí.

IBGE. Fundação Instituto Brasileiro de Geografia e Estatística. População de Santa Catarina. Brasília, DF, 2017. Disponível em:

https://ww2.ibge.gov.br/home/mapa_site/mapa_site.php\#populacao. Acesso em: 5 fev. 2018.

MARCHELLI, Paulo Sérgio. Formação de doutores no Brasil e no mundo: algumas comparações. RBPG, Brasília, DF, v. 2, n. 3, p. 7-29, mar. 2005. 
MEC/INEP. Censo da Educação Superior 2014. Brasília, DF, 2015. Disponível em: http://download.inep.gov.br/educacao_superior/censo_superior/documentos/2015/notas_sobre _o_censo_da_educacao_superior_2014.pdf. Acesso em: 1 jul. 2015.

MEC/INEP. Censo da Educação Superior 2015. Brasília, DF, 2016. Disponível em: http://download.inep.gov.br/educacao_superior/censo_superior/resumo_tecnico/resumo_tecni co_censo_da_educacao_superior_2015.pdf. Acesso em: 18 ago. 2016.

MEC/INEP. Censo da Educação Superior 2016. Brasília, DF, 2017. Disponível em: http://download.inep.gov.br/educacao_superior/censo_superior/resumo_tecnico/resumo_tecni co_censo_da_educacao_superior_2016.pdf. Acesso em: 01 jul. 2017.

MEC/INEP. Censo da Educação Superior 2017. Brasília, DF, 2018a. Disponível em: http://download.inep.gov.br/educacao_superior/censo_superior/resumo_tecnico/resumo_tecni co_censo_da_educacao_superior_2017.pdf. Acesso em: 24 set. 2018.

MEC/INEP. Censo da Educação Superior 2016. Principais resultados. Brasília, DF, 2018b. Disponível em:

http://download.inep.gov.br/educacao_superior/censo_superior/documentos/2016/censo_supe rior_tabelas.pdf. Acesso em: 12 fev. 2018.

MEC/INEP. Censo da Educação Superior 2016. Notas estatísticas. Brasília, DF, 2018c. Disponível em:

http://download.inep.gov.br/educacao_superior/censo_superior/documentos/2016/notas_sobre _o_censo_da_educacao_superior_2016.pdf. Acesso em: 12 fev. 2018.

MEC/INEP/DEAES. Educação Superior Brasileira 1991-2004. Santa Catarina. Brasília: INEP, 2006.

MUNIZ, Milton D. Educação superior em Santa Catarina: consolidação e expansão. 2006, 261 f. Tese (Doutorado em Engenharia de Produção) - Universidade Federal de Santa Catarina, Florianópolis, 2006.

PEGORARO, Ludimar. O terceiro setor e o ensino superior no Brasil: o sistema fundacional catarinense. In: PERONI, Vera Maria Vidal et al. (orgs.). Dilemas da educação brasileira em tempos de globalização neoliberal: entre o público e o privado. Porto Alegre: Ed. da UFRGS, 2006. p. 179-215.

PEGORARO, Ludimar. Terceiro setor na educação superior brasileira. Campinas: Leitura Crítica, 2013.

SANTA CATARINA. SECRETARIA DE ESTADO DA EDUCAÇÃO. Programa de Bolsas Universitárias de Santa Catarina: investimentos. 2017. Disponível em:

http://www.uniedu.sed.sc.gov.br/index.php/pos-graduacao/investimentos. Acesso em: 15 ago. 2018.

SANTA CATARINA. SECRETARIA DE ESTADO DA EDUCAÇÃO. Programa de Bolsas Universitárias de Santa Catarina: estudantes beneficiados. 2017. Disponível em: http://www.uniedu.sed.sc.gov.br/index.php/pos-graduacao/estudantes-beneficiados-posgraduacao. Acesso em: 15 ago. 2018. 
TREVISOL, Joviles Vitório. O ensino superior público na Mesorregião Fronteira Sul: a implantação da UFFS. In: RADIN, J. C.; VALENTINI, D. J.; ZARTH, P. A. História da Fronteira Sul. Porto Alegre: Letra\&Vida; Chapecó: UFFS, 2015a. p. 333-352.

TREVISOL, Joviles Vitório. A pós-graduação na Universidade Federal da Fronteira Sul: interiorização e redução de assimetrias em uma Região de fronteira. RBPG, Brasília, v. 12, n. 28 , p. 505-532, ago. 2015b.

UNIVERSIDADE FEDERAL DE SANTA CATARINA - UFSC. Tradição em produção conhecimento: UFSC celebra 50 anos de pós-graduação. Florianópolis, 2019. Disponível em: https://noticias.ufsc.br/2019/04/tradicao-em-produzir-conhecimento-ufsc-celebra-50-anos-depos-graduacao/. Acesso em: 10 jun. 2019. 